\title{
Safety Evaluation of Oral Toxicity of Carica papaya Linn. Leaves: A Subchronic Toxicity Study in Sprague Dawley Rats
}

\author{
Zakiah Ismail, ${ }^{1}$ Siti Zaleha Halim, ${ }^{1}$ Noor Rain Abdullah, ${ }^{1,2}$ Adlin Afzan, ${ }^{1}$ \\ Badrul Amini Abdul Rashid, ${ }^{1}$ and Ibrahim Jantan ${ }^{3}$ \\ ${ }^{1}$ Herbal Medicine Research Center, Institute for Medical Research, Jalan Pahang, 50588 Kuala Lumpur, Malaysia \\ ${ }^{2}$ Infectious Disease Research Center, Institute for Medical Research, Jalan Pahang, 50588 Kuala Lumpur, Malaysia \\ ${ }^{3}$ Drug and Herbal Research Center, Faculty of Pharmacy, Universiti Kebangsaan Malaysia, Jalan Raja Muda Abdul Aziz, \\ 50300 Kuala Lumpur, Malaysia
}

Correspondence should be addressed to Siti Zaleha Halim; ctzaleha.h2@gmail.com

Received 28 February 2014; Accepted 28 July 2014; Published 29 October 2014

Academic Editor: Mahmood A. Abdulla

Copyright @ 2014 Zakiah Ismail et al. This is an open access article distributed under the Creative Commons Attribution License, which permits unrestricted use, distribution, and reproduction in any medium, provided the original work is properly cited.

\begin{abstract}
The subchronic toxicity effect of the leaf extract of Carica papaya Linn. in Sprague Dawley (SD) rats was investigated in this study. The extract was prepared by dissolving the freeze dried extract of the leaves in distilled water and was administered orally to SD rats (consisted of $10 \mathrm{rats} / \mathrm{sex} / \mathrm{group}$ ) at 0 (control), 0.01, 0.14, and $2 \mathrm{~g} / \mathrm{kg}$ body weight (BW) for 13 weeks. General observation, mortality, and food and water intake were monitored throughout the experimental period. Hematological and biochemical parameters, relative organ weights, and histopathological changes were evaluated. The study showed that leaf extract when administered for 13 weeks did not cause any mortality and abnormalities of behavior or changes in body weight as well as food and water intake. There were no significant differences observed in hematology parameters between treatment and control groups; however significant differences were seen in biochemistry values, for example, LDH, creatinine, total protein, and albumin. However, these changes were not associated with histopathological changes. In conclusion, the results suggested that daily oral administration of rats with C. papaya leaf extract for 13 weeks at a dose up to fourteen times the levels employed in traditional medicine practice did not cause any significant toxic effect.
\end{abstract}

\section{Introduction}

Carica papaya Linn. (family: Caricaceae) is primarily cultivated for its fruit and the young leaves are consumed as a vegetable by the Malay community in Malaysia. Different parts of the plant have been used in traditional medicine to treat various diseases. The juice of the green leaves is consumed as beverage to treat malarial fever [1]. The leaves are also used to treat digestive disorders and other disturbances of the gastrointestinal tract. The fruit is used to treat high fever, cough, and anorexia and the seed has been used to treat digestive disorders, to improve protein digestion, and to expel intestinal worms [2]. The root is used to treat urinary disorders while the bark is used to treat toothache [3].

Many studies have been conducted to evaluate the biological activities of various parts of $C$. papaya. The fruit and seed of C. papaya have showed bacteriostatic activity against several enteropathogens in human [4]. It was reported that experimentally induced diabetic rats showed significant wound healing after treatment with the aqueous extract of the fruit of C. papaya [5]. The aqueous extract of the leaves of the plant showed significant protective effect against alcohol induced oxidative damage to the gastric mucosa in rats [6], and it was effective in healing induced wound in rats [7]. The aqueous extract of the leaves also exhibited the ability to inhibit tumor cell lines [8] and this activity was potentiated with phenolic compounds $[9,10]$. Xanthine oxidase was found to be present in the leaf extract and thus it has potential to work as an anti-gout agent [11]. The crude ethyl acetate extract of $C$. papaya leaves showed high antiplasmodial activity against Plasmodium falciparum and $P$. falciparum-resistant strains [12]. The ethanol extract of 
C. papaya leaves showed potential as a source of drugs against urinary tract microbes [13].

Phytochemical studies on the leaves of C. papaya showed the presence of various compounds including piperidine alkaloids such as carpaine, pseudocarpaine, and dehydrocarpaines I and II [14-17]. The alkaloids have been shown to be teratogenic to livestock as they were found to inhibit the fetal movement [18] and exhibited antiamoebic activity [19]. Ekong et al. [20] also reported that the aqueous extract of C. papaya leaves given to pregnant rats showed some defects in fetus. The leaves can be considered to possess some nutritional value as they were found to contain multinutrients and iron [21]. Recently we identified carpaine, malic acid, quinic acid, six malic acid derivatives, and four flavonol glycosides in the leaf extract of the plant [22].

Toxicity evaluation of C. papaya leaves becomes more important as they are not only consumed widely as food but also prepared and used as a traditional medicine. Acute toxicity study which involved a single dose administration of C. papaya leaf juice and is followed by fourteen days' observation in rats up to $2 \mathrm{~g} / \mathrm{kg}$ BW showed dehydration as demonstrated by an increase in red cell mass [23]. We have also carried out a repeated dose 28-day oral toxicity study of the leaf extract in rats (subacute toxicity study) and the results indicated that the plant extract did not cause mortality, there were no treatment-related changes, and all organs did not reveal morphological alterations [22]. We also have carried out a clinical trial to investigate the platelet elevating property in dengue patients after having received C. papaya leaf juices for 3 consecutive days [24].

The present study, a subchronic toxicity evaluation of $C$. papaya leaf extract, was carried out to determine long term consumption effect after repeated doses of C. papaya leaf extract in a thirteen-week oral toxicity study.

\section{Materials and Methods}

2.1. Plant Material. The fresh leaves of Carica papaya L. "Sekaki" were purchased by the Malaysian Agricultural Research and Development Institute (MARDI). A representative sample of this plant was authenticated at the Forest Research Institute Malaysia (FRIM), Kepong, with voucher specimen number 007/10. Leaves were collected and washed under running tap water and then cut into small pieces and juice was extracted using a juicer (Panasonic, Shah Alam, Malaysia). The resulting juice, without addition of water, was then poured into a glass container and left frozen in a freezer. The juice was lyophilized resulting in a dark green powder $(2.6 \% \mathrm{w} / \mathrm{w}$ yield). Phytochemical analysis had been carried out for chemical fingerprinting [22]. The doses used in the toxicity study were calculated based on the body weight (BW) of the rats. The test samples were prepared by dissolving the powder in distilled water to obtain concentrations of 0.01 , 0.14 , and $2 \mathrm{~g} / \mathrm{kg} \mathrm{BW}$.

2.2. Animals. Male and female Sprague Dawley (SD) rats aged between six and seven weeks and weighed between 90 and $100 \mathrm{~g}$ were used in this study. The SD rats were obtained from the Laboratory Animal Resource Unit, Medical Resource Research Center, Institute for Medical Research (IMR), Kuala Lumpur. The use of laboratory animals and the study design were approved by the Institutional Animal Care and Used Committee (IACUC) (ACUC number ACUC/ KKM 02 (1/2009)). The Guidelines of Handling of Laboratory Animals by the Ministry of Health Malaysia were followed throughout the experiments [25].

The animals were housed individually in a stainless-steel wire-mesh cage with size $6 \mathrm{H} \times 11 \mathrm{D} \times 16 \mathrm{~W} \mathrm{~cm}$ and maintained at room temperature $\left(27 \pm 2^{\circ} \mathrm{C}\right)$ with humidity of $65.85 \pm$ $6.76 \%$ and with $12 \mathrm{~h}$ alternate artificial and natural light and dark cycle. Room temperature and relative humidity were recorded daily using a temperature datalogger (TempRH Datalogger BG-DL-01/01B). Each animal was identified by a cage card. They were fed with a pellet diet with Zeigler Rodent NIH-31 irradiated auto wafer feeds (Zeigler Bros, Pennsylvania, USA) and given an unlimited supply of reverse osmosis water. The animals were acclimatized to laboratory conditions for seven days prior to the experiments.

2.3. Experimental Design. The subchronic toxicity study was carried out according to the OECD Guidelines for the "Repeated Dose 90-day Oral Toxicity Study in Rodents," no. 408 [26] with some modifications. The modifications were in the temperature and humidity of the room. Forty female and 40 male rats were randomly assigned into four groups which were made up of one control group and three treatment groups ( $n=10$ rats/sex/group). The treatment group received lyophilized $C$. papaya leaf juice diluted in water to the necessary dosage while the control group received water only.

\subsection{Selection of Doses and Oral Administration of the Extracts.} Dose selection was based on the acute toxicity and subacute toxicity studies carried out previously, where the highest dose of $2 \mathrm{~g} / \mathrm{kg}$ BW did not exhibit any acute effects on the rats (NOAEL) [23]. Therefore, a dose of $2 \mathrm{~g} / \mathrm{kg}$ BW was selected for the highest dose in this study. The medium $(0.14 \mathrm{~g} / \mathrm{kg}$ BW) and low dose $(0.01 \mathrm{~g} / \mathrm{kg} \mathrm{BW})$ levels were selected based on the local traditional preparation of C. papaya juice for treatment of fever in humans. The $C$. papaya leaf juice at different concentrations was administered orally using intubation needle on a daily basis for 13 weeks. The rats were weighed weekly and the amount of $C$. papaya leaf juice to be given was recalculated based on the new body weight to ensure a constant dose volume per kg BW at all times. Control rats were administered the same volume of drinking water as the amount given to the test groups.

\subsection{Parameters Measured during the Study}

2.5.1. General Observation and Mortality. General observations were carried out twice daily for mortality, moribund and ill health, or reaction to treatment. These observations include changes in skin, fur, eyes, mucus membranes, behavior pattern, tremors, salivation, diarrhea, sleep, and coma. The observation was carried out according to the Guidance Document on the Recognition, Assessment and Use of Clinical 
Signs as Humane Endpoints for Experimental Animals Used in Safety Evaluation [27].

2.5.2. Body Weight and Food and Water Consumption. Individual rat was weighed before the commencement of the experiment and then weighed once on day 7 of every week. Final body weights were recorded prior to the scheduled necropsy. Each cage was supplied with calculated amounts of food and water. The amounts of left over food and water were measured weekly and the differences were regarded as food (g/rat/week) and water consumption (mL/rat/week).

2.5.3. Hematological and Biochemical Analysis. The rats were fasted overnight by removing all food from the cages but were allowed access to water ad libitum before blood was collected. Rats were anaesthetized with light ether and blood samples were collected via direct heart puncture and put into two types of tubes, one with anticoagulant (EDTA) and the other without any additives. After withdrawing blood from the rats, they were sacrificed with an overdose of ether. The anticoagulated blood samples (EDTA) were analyzed immediately for hematology parameters using Hematology Analyzer (Medonic CA 620 VET, Stockholm, Sweden). These parameters include total and differential leukocyte count (WBC), erythrocyte counts (RBC), hemoglobin concentration (HGB), hematocrit (HCT), mean cell volume (MCV), mean corpuscular hemoglobin $(\mathrm{MCH})$, mean corpuscular hemoglobin concentration (MCHC), and platelet counts (PLT). The blood without any additives was used in the biochemistries and the parameters which include serum total protein, albumin, alkaline phosphatase (ALP), aspartate aminotransferase (AST), alanine aminotransferase (ALT) urea, creatinine, uric acid, creatinine kinase (CK), lactate dehydrogenase (LDH), $\alpha$-hydroxybutyrate dehydrogenase $(\mathrm{HBDH})$, cholesterol, triglycerides, and glucose were determined. The tests were done using the biochemistry analyser (Vitalab Selecta, E-series, Netherlands).

2.5.4. Gross Findings and Organ Weights. Complete postmortem examinations were carried out on all animals. The rats were dissected, and their internal organs were carefully examined for any pathological changes. Subsequently the organs were removed and weighed. The organs were the lungs, heart, liver, stomach, spleen, gastrointestinal, kidneys, testes, and adrenals. The relative organ weight (ROW) of each organ was calculated using the following equation:

$$
\begin{aligned}
\text { ROW }= & {\left[\frac{\text { Absolute organ weight }(\mathrm{g})}{\text { Body weight of rat on sacrifice day }(\mathrm{g})}\right] } \\
& \times 100 .
\end{aligned}
$$

The organs were preserved in $10 \%$ buffered formalin for subsequent histopathological examination.

2.5.5. Histopathology. For histopathological examination, a representative tissue or the whole organ (depending on the size and weight) was taken and processed further to make

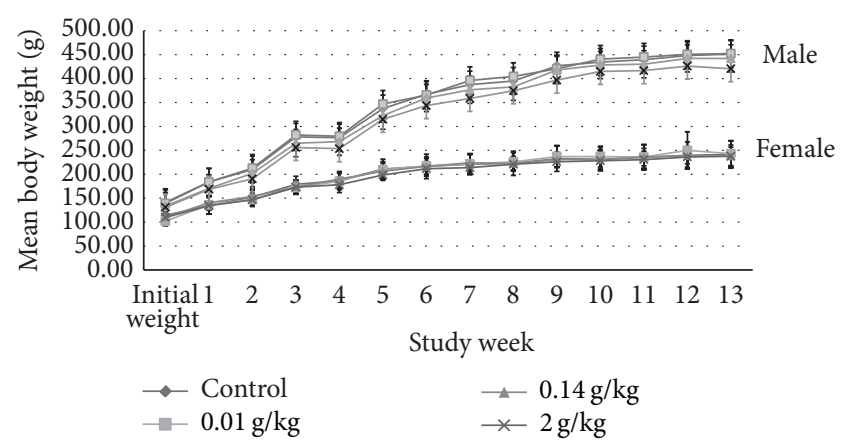

FIgURE 1: Mean body weight ( $\mathrm{g}$ ) of male and female rats administered daily after subchronic treatment orally for 13 weeks with C. papaya leaf extract in SD rats. Values are expressed as mean \pm standard deviation ( $n=10$ /group).

slides using the standard procedure for histology slides and was stained with Hematoxylin and Eosin. The slides were examined using a light microscope (Olympus BX 51, Tokyo, Japan).

2.6. Statistical Analysis. The data were analyzed using SPSS program, version 14 . The one-way analysis of variance (ANOVA) was used to test for significant differences between the experimental groups and was followed by Tukey's HSD for multiple comparisons [28, 29]. Nonparametric test methods were used when the distribution of certain variable(s) differed from normal. The nonparametric methods employed were the Kruskal-Wallis test for pairwise comparison. Results with $P<0.05$ were considered statistically significant. The results were expressed as mean value $(x)$ and standard deviation (SD) for each variable measured.

\section{Results}

3.1. Survival and General Observation. There was no treatment related death reported in any of the experiment groups as well as in the control group. Neither physical nor behavioral changes were observed in any of the groups throughout the study period of 13 weeks.

3.2. Body Weight Changes and Food and Water Consumption. The initial (day 0) body weights of the female rats were $436.00 \pm 2.33 \mathrm{~g}$, whereas for the male rats were $545.00 \pm 1.14 \mathrm{~g}$. Their body weights were gradually increased as noted in weekly measurements and presented in Figure 1. No significant difference in body weight changes was noted between the control group and any of the treated groups at any time of the 13-week period. The male test group receiving medium dose in week 3 and week 10 showed significant increase in food consumption $(P=0.008, P=0.012$, resp.) (Figure 2). While the female test group which received medium dose showed significant decrease $(P=0.010)$ in food consumption during week 1 (Figure 3). However, there is no significant difference in the amount of water consumed in all various 


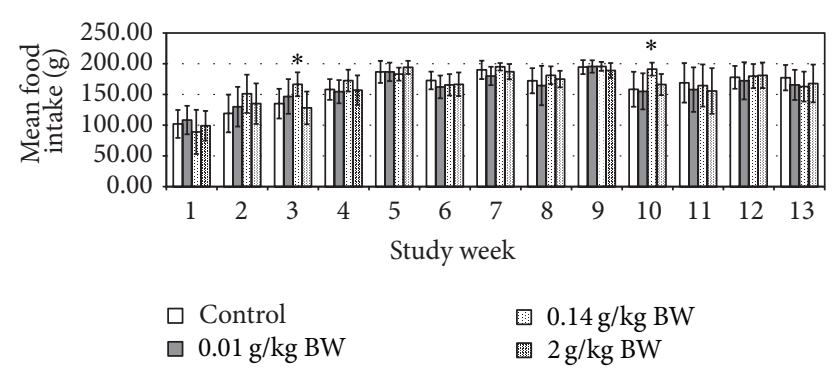

FIGURE 2: Mean food intake (g) of rats administered daily after subchronic treatment orally for 13 weeks with $C$. papaya leaf extract in male SD rats. Values are expressed as mean \pm standard deviation ( $n=10$ /group). $\left({ }^{*}\right) P<0.05$ significant value.

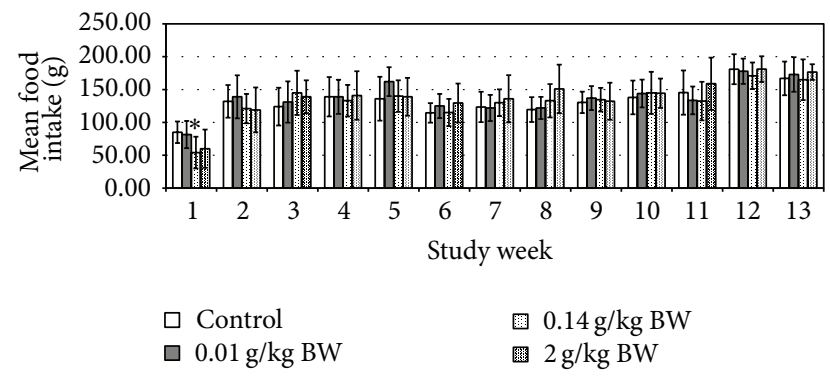

Figure 3: Mean food intake (g) of rats administered daily after subchronic treatment orally for 13 weeks with C. papaya leaf extract in female SD rats. Values are expressed as mean \pm standard deviation ( $n=10$ /group). $\left({ }^{*}\right) P<0.05$ significant value.

groups, including the control, throughout the study period (Figures 4 and 5, resp.).

3.3. Hematology and Biochemistry. The hematological and the biochemistry values are presented in Tables 1 and 2, respectively. There were no significant changes seen in all the hematological parameters amongst the different treatment groups as well as the control group for both male and female rats. However, for biochemistry values, some significant changes were seen. In the male rats treated with medium dose, they showed significant increase in albumin and LDH level $(P=0.001$ and $P=0.005$, resp.). While rats were treated with high dose, a significant decrease in creatinine and a significant increase in $\operatorname{LDH}(P=0.001$ and $P=0.020$, resp. $)$ were seen. The female rats treated with medium and high doses showed a significant increase in total protein $(P=0.005$ and $P=0.001$, resp.). The albumin values for rats treated with medium and high doses were significantly decreased with $P=0.001$ and $P=0.001$, respectively. The creatinine value was significantly decreased in rats treated with high dose $(P=0.005)$. The glucose value was significantly increased $(P=0.031)$ in rats treated with low dose.

3.4. Organs Weight Changes. As mentioned above in the methodology, the body weight and organ weight of individual rats were recorded at necropsy. The relative organ weight

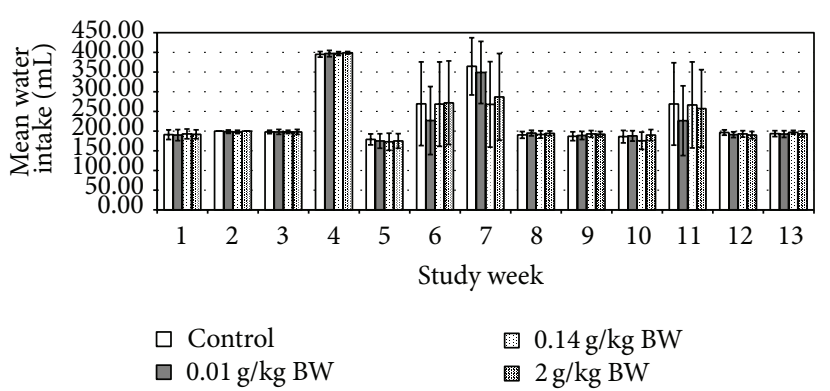

FIGURE 4: Mean water intake $(\mathrm{mL})$ of rats administered daily after subchronic treatment orally for 13 weeks with C. papaya leaf extract in female SD rats. Values are expressed as mean \pm standard deviation ( $n=10$ /group).

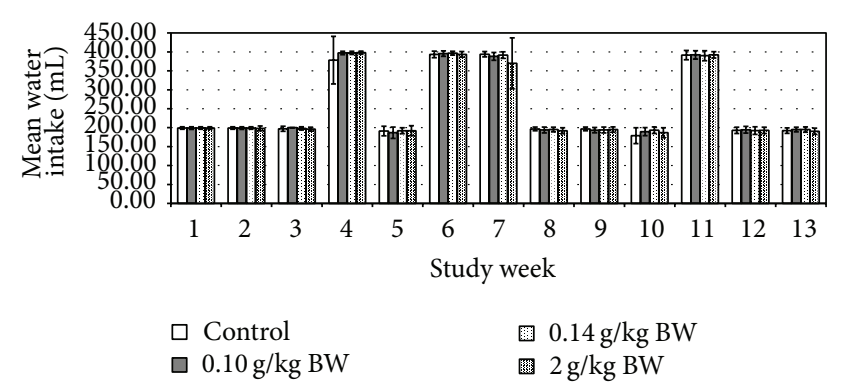

FIGURE 5: Mean water intake $(\mathrm{mL})$ of rats administered daily after subchronic treatment orally for 13 weeks with C. papaya leaf extract in male SD rats. Values are expressed as mean \pm standard deviation ( $n=10$ /group).

(ROW) of each organ was calculated. The data showed that there were no significant differences in all the relative organs weights as compared to the control rats (Table 3 ).

3.5. Histopathology. Histological examination revealed no significant changes in all the organs examined including liver as compared to the control groups, some parts of the picture from the histopathology in Figure 6. They were normal compared to the control group.

\section{Discussion}

Safety of long term use or consumption of medicinal plants is becoming important as most of this preparation will be for general health and will be used for long term duration. In order to elucidate such information, a proper toxicological evaluation is carried out in various experimental animal models to predict toxicity and to select a "safe" dose for human use. Subsequent to that, the safety data on human subject should be conducted through the various phases of clinical trial.

General toxicity studies will normally include acute toxicity, subacute toxicity, and chronic or subchronic toxicity studies. As mentioned earlier, both acute and subacute toxicity studies had been conducted on C. papaya leaves juice and both showed no significant findings that lead to meaningful 
TABLE 1: Hematological values of control group and rats treated with C. papaya leaf extract measured during the subchronic toxicity study.

\begin{tabular}{|c|c|c|c|c|}
\hline Male rats & Control & $0.01 \mathrm{~g} / \mathrm{kg} \mathrm{BW}$ & $0.14 \mathrm{~g} / \mathrm{kg} \mathrm{BW}$ & $2 \mathrm{~g} / \mathrm{kg} \mathrm{BW}$ \\
\hline $\mathrm{WBC}\left(10^{3} / \mu \mathrm{L}\right)$ & $4.74 \pm 2.04$ & $6.01 \pm 2.84$ & $3.69 \pm 1.55$ & $6.24 \pm 2.73$ \\
\hline $\mathrm{RBC}\left(10^{6} \times \mu \mathrm{L}\right)$ & $7.89 \pm 0.42$ & $7.96 \pm 0.40$ & $7.88 \pm 0.51$ & $8.03 \pm 0.37$ \\
\hline $\mathrm{HGB}(\mathrm{g} / \mathrm{dL})$ & $16.30 \pm 0.49$ & $16.13 \pm 0.72$ & $16.27 \pm 0.81$ & $16.34 \pm 0.73$ \\
\hline HCT (\%) & $40.08 \pm 1.42$ & $39.83 \pm 1.97$ & $40.11 \pm 1.87$ & $39.97 \pm 1.86$ \\
\hline MCV (fL) & $50.84 \pm 1.69$ & $49.98 \pm 1.32$ & $50.94 \pm 1.74$ & $49.79 \pm 1.55$ \\
\hline $\mathrm{MCH}(\mathrm{pg})$ & $20.69 \pm 0.74$ & $20.24 \pm 0.53$ & $20.67 \pm 0.54$ & $20.38 \pm 0.56$ \\
\hline MCHC (g/dL) & $40.70 \pm 0.50$ & $40.51 \pm 0.42$ & $40.58 \pm 0.49$ & $40.93 \pm 0.50$ \\
\hline $\operatorname{PLT}\left(10^{3} / \mu \mathrm{L}\right)$ & $637.67 \pm 100.04$ & $697.88 \pm 69.91$ & $563.44 \pm 209.03$ & $718.67 \pm 111.74$ \\
\hline Female rats & Control & $0.01 \mathrm{~g} / \mathrm{kg} \mathrm{BW}$ & $0.14 \mathrm{~g} / \mathrm{kg}$ BW & $2 \mathrm{~g} / \mathrm{kg}$ BW \\
\hline $\mathrm{WBC}\left(10^{3} / \mu \mathrm{L}\right)$ & $2.13 \pm 0.98$ & $1.71 \pm 0.97$ & $1.65 \pm 1.25$ & $3.40 \pm 2.41$ \\
\hline $\mathrm{RBC}\left(10^{6} \times \mu \mathrm{L}\right)$ & $7.22 \pm 0.45$ & $7.05 \pm 0.21$ & $6.89 \pm 0.51$ & $6.85 \pm 0.68$ \\
\hline $\mathrm{HGB}(\mathrm{g} / \mathrm{dL})$ & $15.57 \pm 0.79$ & $15.16 \pm 0.38$ & $14.61 \pm 1.09$ & $14.38 \pm 1.29$ \\
\hline HCT (\%) & $37.57 \pm 1.97$ & $36.55 \pm 0.98$ & $35.45 \pm 2.83$ & $34.70 \pm 3.29$ \\
\hline MCV (fL) & $52.08 \pm 1.59$ & $51.87 \pm 0.97$ & $51.45 \pm 1.04$ & $50.70 \pm 1.81$ \\
\hline $\mathrm{MCH}(\mathrm{pg})$ & $21.59 \pm 0.72$ & $21.52 \pm 0.46$ & $21.23 \pm 0.42$ & $21.04 \pm 0.67$ \\
\hline MCHC (g/dL) & $41.47 \pm 0.62$ & $41.49 \pm 0.48$ & $41.29 \pm 0.60$ & $41.54 \pm 0.45$ \\
\hline $\operatorname{PLT}\left(10^{3} / \mu \mathrm{L}\right)$ & $708.40 \pm 117.74$ & $681.70 \pm 56.09$ & $464.50 \pm 272.37$ & $535.00 \pm 290.60$ \\
\hline
\end{tabular}

Values are expressed as mean \pm standard deviation ( $n=10$ group). WBC: white blood cells, RBC: red blood cells, HGB: Hemoglobin, HCT: hematocrit, MCV: mean corpuscular volume, $\mathrm{MCH}$ : mean cell hemoglobin, $\mathrm{MCHC}$ : mean corpuscular hemoglobin concentration, and PLT: platelet. ${ }^{*} P$ value less than 0.05 ( $P<$ $0.05)$, significant value.

interpretation of toxic effect. The acute toxicity study of C. papaya leaf juice in rats showed dehydration as demonstrated by an increase in red cell mass [23]. We have also carried out a repeated dose 28-day oral toxicity study of a similar leaf extract in rats and the results indicated that the plant extract did not cause mortality, there were no treatment-related changes, and all organs did not reveal morphological alterations [22]. However the biochemistry values (total protein, AST, ALT, and ALP) revealed some changes although they are non-dose dependent. Thus, a subchronic toxicity evaluation of C. papaya leaf extract is necessary to confirm the finding especially when the dosing is given for a longer period in this thirteen-week oral toxicity study. The same aqueous juice extract of C. papaya leaves was also used in this study and such formulation was the form that traditionally had been consumed [30].

From the above presented result, it was showed that daily administration of the C. papaya leaves juice for 13 weeks at the chosen doses did not show any changes in the general behaviors of treated rats, all gained weight normally corresponding to the food and water intake. It was noted that during weeks $4,6,7$, and 11 the water intake was increased in both female and male rats in all groups. However there were no significant differences between groups as compared to the control group. These increases of water intake did not show any change or directly proportional to body weight and food intake; hence, it was more of an accidental finding and was not related to the administration of C. papaya leaf juice. As evidenced by the absence of toxic symptoms, there were no changes in food intake and body weight in those weeks. As seen in the previous studies, there were no hematological changes seen in all the parameters measured including the platelets and hematocrits.

The biochemistry values showed some significant changes in the liver enzymes as in the previous 2 studies; however there is no dose related pattern was observed. At the current subchronic study, all the liver enzymes (AST, ALT, and ALP) except LDH were not significantly different from the control group in both male and female rats. The $\mathrm{LDH}$ was seen to be increasing significantly but only in male group with medium (with increased albumin) and high doses (with decreased level of creatinine), while in female group, such finding was not noted. Previous researchers describe possible liver dysfunction when such studies were conducted for the herbal product/plant. Everds [31] reported that an increase in albumin level maybe associated to abnormal liver function or dehydration state. As discussed by Ramaiah [32], abnormality in AST, ALT, and ALP levels is more specific for liver cell injury. Garba and Ubom [33] and Kotoh et al. [34] reported that $\mathrm{LDH}$ also can be used as indicator in liver cell injures as the enzymes are released from the injured hepatocytes although the specificity to indicate liver disease is lower compared with AST, ALT and ALP. This is due to the fact that serum LDH in liver more rapidly declines and also might indicate the presence of red cell hemolysis rather than liver cell injuries. The other authors, Preus et al. [35] and Oloyede and Sunmonu [36], mention the $\mathrm{LDH}$ as a useful indicator for cardiac damage. In the current study, the finding is most 
TABLE 2: Biochemistry values of control group and rats treated with C. papaya leaf extract measured during the subchronic toxicity study.

\begin{tabular}{|c|c|c|c|c|}
\hline Male rats & Control & $0.01 \mathrm{~g} / \mathrm{kg} \mathrm{BW}$ & $0.14 \mathrm{~g} / \mathrm{kg} \mathrm{BW}$ & $2 \mathrm{~g} / \mathrm{kg} \mathrm{BW}$ \\
\hline \multicolumn{5}{|l|}{ Liver profile } \\
\hline Total protein $(\mathrm{g} / \mathrm{L})$ & $57.22 \pm 2.44$ & $59.13 \pm 4.76$ & $59.11 \pm 5.73$ & $60.89 \pm 8.18$ \\
\hline Albumin $(\mathrm{g} / \mathrm{L})$ & $27.51 \pm 2.90$ & $28.60 \pm 2.70$ & $32.32 \pm 2.19^{*}$ & $29.67 \pm 1.75$ \\
\hline $\operatorname{ALP}(\mathrm{U} / \mathrm{L})$ & $147.38 \pm 33.20$ & $173.13 \pm 61.47$ & $192.89 \pm 60.99$ & $218.22 \pm 98.43$ \\
\hline AST (U/L) & $186.38 \pm 28.16$ & $166.63 \pm 41.81$ & $169.67 \pm 37.53$ & $158.22 \pm 39.52$ \\
\hline $\operatorname{ALT}(\mathrm{U} / \mathrm{L})$ & $49.50 \pm 8.62$ & $46.75 \pm 7.17$ & $61.22 \pm 23.63$ & $60.78 \pm 29.82$ \\
\hline \multicolumn{5}{|l|}{ Renal profile } \\
\hline Urea $(\mathrm{mmol} / \mathrm{L})$ & $6.75 \pm 0.51$ & $6.14 \pm 1.12$ & $6.73 \pm 0.68$ & $5.73 \pm 1.22$ \\
\hline Creatinine $(\mu \mathrm{mol} / \mathrm{L})$ & $56.25 \pm 8.99$ & $51.75 \pm 7.13$ & $49.89 \pm 8.10$ & $40.33 \pm 16.38^{*}$ \\
\hline Uric acid $(\mu \mathrm{mol} / \mathrm{L})$ & $117.23 \pm 50.93$ & $81.53 \pm 25.60$ & $161.33 \pm 98.28$ & $95.80 \pm 43.12$ \\
\hline \multicolumn{5}{|l|}{ Cardiac profile } \\
\hline $\mathrm{CK}(\mathrm{U} / \mathrm{L})$ & $1408.250 \pm 534.91$ & $1187.25 \pm 208.64$ & $1589.11 \pm 588.53$ & $1448.78 \pm 478.84$ \\
\hline $\mathrm{LDH}(\mathrm{U} / \mathrm{L})$ & $2014.67 \pm 500.68$ & $2187.38 \pm 875.63$ & $2706.00 \pm 645.85$ & $2952.78 \pm 259.86^{*}$ \\
\hline HBDH (U/L) & $648.33 \pm 119.92$ & $612.63 \pm 199.95$ & $648.00 \pm 161.63$ & $589.00 \pm 106.74$ \\
\hline \multicolumn{5}{|l|}{ Lipid profile } \\
\hline Cholestrol $(\mathrm{mmol} / \mathrm{L})$ & $1.39 \pm 1.18$ & $1.12 \pm 0.53$ & $1.21 \pm 0.21$ & $1.27 \pm 0.28$ \\
\hline Triglycerides $(\mathrm{mmol} / \mathrm{L})$ & $0.97 \pm 0.51$ & $0.80 \pm 0.30$ & $1.27 \pm 0.22$ & $1.26 \pm 0.31$ \\
\hline Glucose $(\mathrm{mmol} / \mathrm{L})$ & $7.97 \pm 2.68$ & $6.96 \pm 2.01$ & $10.31 \pm 5.47$ & $7.68 \pm 2.84$ \\
\hline Female rats & Control & $0.01 \mathrm{~g} / \mathrm{kg} \mathrm{BW}$ & $0.14 \mathrm{~g} / \mathrm{kg} \mathrm{BW}$ & $2 \mathrm{~g} / \mathrm{kg} \mathrm{BW}$ \\
\hline \multicolumn{5}{|l|}{ Liver profile } \\
\hline Total protein $(\mathrm{g} / \mathrm{L})$ & $71.80 \pm 4.10$ & $71.33 \pm 3.84$ & $89.00 \pm 18.18^{*}$ & $87.33 \pm 6.93^{*}$ \\
\hline $\operatorname{Albumin}(\mathrm{g} / \mathrm{L})$ & $44.84 \pm 2.54$ & $44.43 \pm 2.26$ & $34.92 \pm 5.08^{*}$ & $32.58 \pm 2.22^{*}$ \\
\hline $\operatorname{ALP}(\mathrm{U} / \mathrm{L})$ & $119.20 \pm 53.88$ & $169.78 \pm 80.00$ & $70.30 \pm 51.41$ & $95.78 \pm 40.09$ \\
\hline AST (U/L) & $274.20 \pm 47.48$ & $276.78 \pm 83.09$ & $268.80 \pm 147.28$ & $215.89 \pm 72.40$ \\
\hline $\operatorname{ALT}(\mathrm{U} / \mathrm{L})$ & $70.80 \pm 18.50$ & $85.89 \pm 21.74$ & $63.10 \pm 33.51$ & $52.33 \pm 25.07$ \\
\hline \multicolumn{5}{|l|}{ Renal profile } \\
\hline Urea $(\mathrm{mmol} / \mathrm{L})$ & $9.21 \pm 1.45$ & $8.78 \pm 1.00$ & $7.51 \pm 2.11$ & $7.38 \pm 2.13$ \\
\hline Creatinine $(\mu \mathrm{mol} / \mathrm{L})$ & $78.56 \pm 10.76$ & $83.56 \pm 14.04$ & $69.70 \pm 14.09$ & $57.67 \pm 8.20^{*}$ \\
\hline Uric acid $(\mu \mathrm{mol} / \mathrm{L})$ & $277.52 \pm 119.04$ & $440.73 \pm 185.39$ & $359.33 \pm 195.94$ & $247.36 \pm 97.58$ \\
\hline \multicolumn{5}{|l|}{ Cardiac profile } \\
\hline $\mathrm{CK}(\mathrm{U} / \mathrm{L})$ & $1675.89 \pm 364.79$ & $1514.75 \pm 517.94$ & $1530.30 \pm 671.40$ & $1739.11 \pm 1163.74$ \\
\hline $\mathrm{LDH}(\mathrm{U} / \mathrm{L})$ & $1481.50 \pm 871.06$ & $2265.50 \pm 852.88$ & $1561.70 \pm 593.89$ & $1683.11 \pm 668.59$ \\
\hline HBDH (U/L) & $1027.78 \pm 302.57$ & $867.00 \pm 171.88$ & $888.50 \pm 123.73$ & $817.25 \pm 148.18$ \\
\hline \multicolumn{5}{|l|}{ Lipid profile } \\
\hline Cholestrol (mmol/L) & $1.62 \pm 0.23$ & $1.56 \pm 0.23$ & $1.79 \pm 0.41$ & $1.57 \pm 0.29$ \\
\hline Triglycerides (mmol/L) & $1.31 \pm 0.29$ & $1.47 \pm 0.36$ & $1.43 \pm 0.26$ & $1.48 \pm 0.15$ \\
\hline Glucose $(\mathrm{mmol} / \mathrm{L})$ & $8.88 \pm 5.92$ & $15.17 \pm 5.62^{*}$ & $9.24 \pm 3.04$ & $6.85 \pm 1.73$ \\
\hline
\end{tabular}

Values are expressed as mean \pm standard deviation $(n=10$ /group). ALP: alkaline phosphatase, AST: aspartate aminotransferase, ALT: alanine aminotransferase, CK: creatinine kinase, LDH: lactate dehydrogenase, and $\mathrm{HBDH}: \alpha$-hydroxybutyrate dehydrogenase. ${ }^{*} P$ value less than $0.05(P<0.05)$, significant value.

likely to indicate liver damaged rather than red cell hemolysis or cardiac damaged although the other specific liver enzymes AST, ALT, and ALP were not significantly different, whereas in the female group, the medium and high group showed significant increase in total protein, $P=0.005$ and $P=$ 0.001 , respectively, but their albumin values were significantly decreased with $P=0.001$ and $P=0.001$, respectively. This could be due to the fact that other protein fractions other than albumin might be increased and thus need to be further investigated.

As the rats are aging and their size increases, their physical activities reduced and hence this could be the explanation for the significant reduction of creatinine level in both male and female rats treated with the highest dose. This is in 
TABLE 3: Organ weight values of control group and rats treated with C. papaya leaf extract measured during the subchronic toxicity study. The relative organ weight per $100 \mathrm{~g}$ body weight recorded at the end of the study.

\begin{tabular}{|c|c|c|c|c|}
\hline Organ & Control & $0.01 \mathrm{~g} / \mathrm{kg} \mathrm{BW}$ & $0.14 \mathrm{~g} / \mathrm{kg} \mathrm{BW}$ & $2 \mathrm{~g} / \mathrm{kg} \mathrm{BW}$ \\
\hline \multicolumn{5}{|l|}{ Male rats } \\
\hline Lung & $0.31 \pm 0.03$ & $0.36 \pm 0.09$ & $0.37 \pm 0.07$ & $0.35 \pm 0.08$ \\
\hline Heart & $0.27 \pm 0.02$ & $0.29 \pm 0.05$ & $0.27 \pm 0.02$ & $0.27 \pm 0.03$ \\
\hline Liver & $2.87 \pm 0.14$ & $3.05 \pm 0.66$ & $2.80 \pm 0.37$ & $2.82 \pm 0.27$ \\
\hline Stomach & $0.38 \pm 0.03$ & $0.38 \pm 0.05$ & $0.39 \pm 0.06$ & $0.37 \pm 0.05$ \\
\hline Spleen & $0.13 \pm 0.02$ & $0.15 \pm 0.01$ & $0.15 \pm 0.01$ & $0.15 \pm 0.03$ \\
\hline GIT & $0.34 \pm 0.13$ & $0.36 \pm 0.08$ & $0.28 \pm 0.08$ & $0.32 \pm 0.09$ \\
\hline Kidney (left) & $0.31 \pm 0.03$ & $0.30 \pm 0.06$ & $0.29 \pm 0.02$ & $0.29 \pm 0.03$ \\
\hline Kidney (right) & $0.32 \pm 0.03$ & $0.29 \pm 0.05$ & $0.29 \pm 0.02$ & $0.29 \pm 0.03$ \\
\hline Testis (left) & $0.35 \pm 0.03$ & $0.34 \pm 0.04$ & $0.34 \pm 0.03$ & $0.35 \pm 0.03$ \\
\hline Testis (right) & $0.35 \pm 0.03$ & $0.34 \pm 0.04$ & $0.35 \pm 0.04$ & $0.34 \pm 0.02$ \\
\hline Adrenal (left) & $0.01 \pm 0.00$ & $0.01 \pm 0.00$ & $0.01 \pm 0.00$ & $0.01 \pm 0.00$ \\
\hline Adrenal (right) & $0.01 \pm 0.00$ & $0.01 \pm 0.00$ & $0.01 \pm 0.00$ & $0.00 \pm 0.00$ \\
\hline \multicolumn{5}{|l|}{ Female rats } \\
\hline Lung & $0.46 \pm 0.06$ & $0.45 \pm 0.09$ & $0.44 \pm 0.07$ & $0.45 \pm 0.09$ \\
\hline Heart & $0.32 \pm 0.03$ & $0.31 \pm 0.02$ & $0.31 \pm 0.02$ & $0.31 \pm 0.03$ \\
\hline Liver & $2.95 \pm 0.30$ & $3.02 \pm 0.27$ & $2.85 \pm 0.19$ & $3.02 \pm 0.26$ \\
\hline Stomach & $0.50 \pm 0.07$ & $0.46 \pm 0.07$ & $0.51 \pm 0.08$ & $0.49 \pm 0.08$ \\
\hline Spleen & $0.17 \pm 0.02$ & $0.17 \pm 0.02$ & $0.18 \pm 0.02$ & $0.18 \pm 0.02$ \\
\hline GIT & $0.45 \pm 0.12$ & $0.45 \pm 0.18$ & $0.43 \pm 0.06$ & $0.39 \pm 0.04$ \\
\hline Kidney (left) & $0.30 \pm 0.03$ & $0.29 \pm 0.04$ & $0.29 \pm 0.03$ & $0.31 \pm 0.03$ \\
\hline Kidney (right) & $0.31 \pm 0.03$ & $0.31 \pm 0.03$ & $0.30 \pm 0.02$ & $0.31 \pm 0.02$ \\
\hline Ovary (left) & $0.02 \pm 0.01$ & $0.02 \pm 0.00$ & $0.02 \pm 0.01$ & $0.04 \pm 0.06$ \\
\hline Ovary (right) & $0.02 \pm 0.00$ & $0.02 \pm 0.00$ & $0.02 \pm 0.01$ & $0.02 \pm 0.01$ \\
\hline Adrenal (left) & $0.01 \pm 0.00$ & $0.02 \pm 0.00$ & $0.01 \pm 0.01$ & $0.01 \pm 0.00$ \\
\hline Adrenal (right) & $0.01 \pm 0.01$ & $0.01 \pm 0.00$ & $0.01 \pm 0.00$ & $0.01 \pm 0.01$ \\
\hline
\end{tabular}

Values are expressed as mean \pm standard deviation ( $n=10$ /group).

reference to reports by Omer [37], Attia and Nasr [38] which described that creatinine values were affected by the variation of body weight or physical activity. Creatinine and urea are waste products of protein excreted from kidney and are indicators for kidney damage. Thus this reduction of creatinine indicates that there was no potential kidney effect and this was supported by the urea value which remained normal as compared to the control group.

Tarkang et al. [39] also conducted study on aqueous as well as ethanol extracts of the leaves of C. papaya for 28 and 90 days. The finding showed no abnormalities in liver enzymes and renal biochemistries in rat after administration of C. papaya leaf extract for 28 and 90 days. Only ethanol extract showed some changes in the liver and renal toxicity at the dose $1 \mathrm{~g} / \mathrm{kg}$ BW. This different finding could be due to the fact that different extract was used in the study. It was air-dried and extracted either with water or ethanol, while juice extracted from the fresh leaves was used in this study.

\section{Conclusions}

In conclusion, the administration of rats with low, medium, and high doses of fresh juice of C. papaya leaf extract for 13 weeks did not cause any changes in body weight, food intake, and water level. There were also no significant differences observed in hematology parameters between treatment and control groups. There were significant differences in biochemistry values, such as the $\mathrm{LDH}$, creatinine, total protein, and albumin. However, these changes were not associated with histopathological changes and were not dose dependent. Such finding on possible liver dysfunction needs to be confirmed with proper hepatotoxicity study protocol to elucidate extension of the toxic effect if any. The oral dose of C. papaya leaf extract was more than $2 \mathrm{~g} / \mathrm{kg} \mathrm{BW}$ and no observed adverse effect level (NOAEL) of the extract for both female and male rats was $2 \mathrm{~g} / \mathrm{kg}$ BW per day for 13 weeks extracts on Sprague Dawley rats for the present study. 


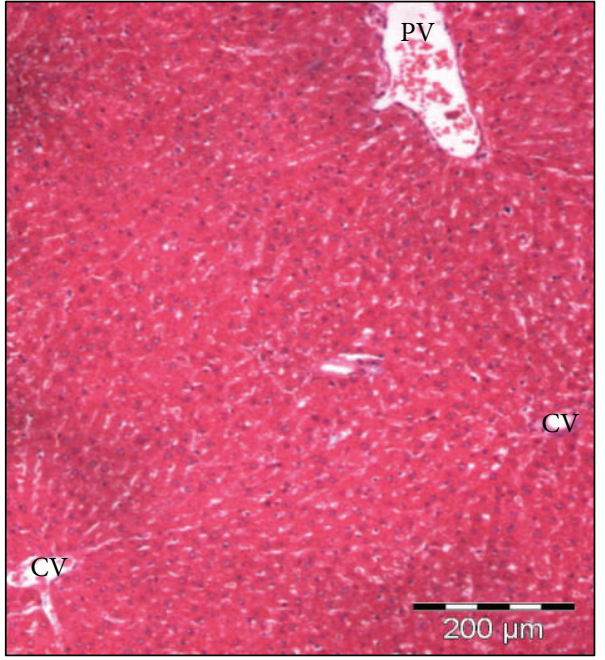

(i)

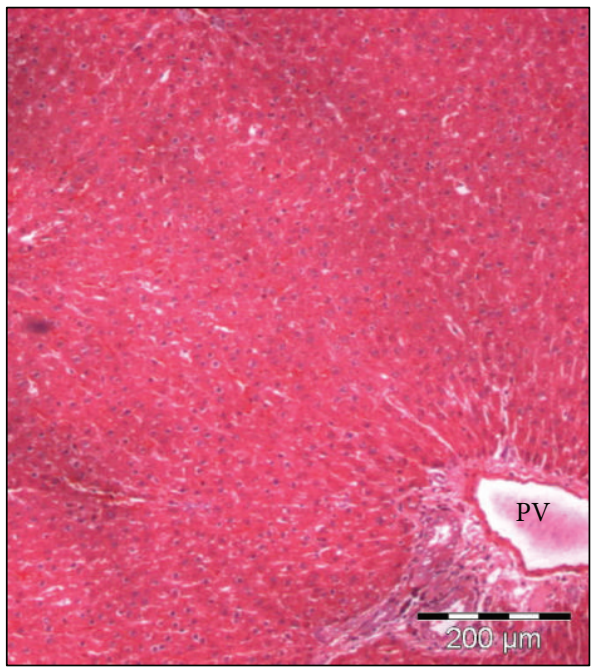

(i)

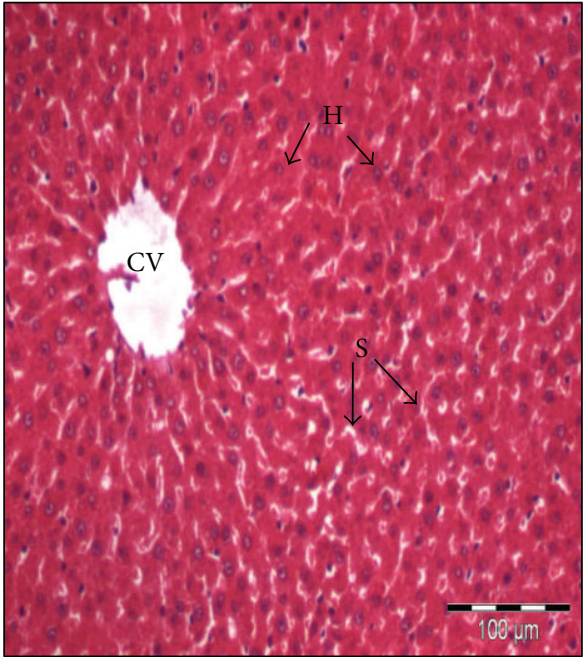

(ii)

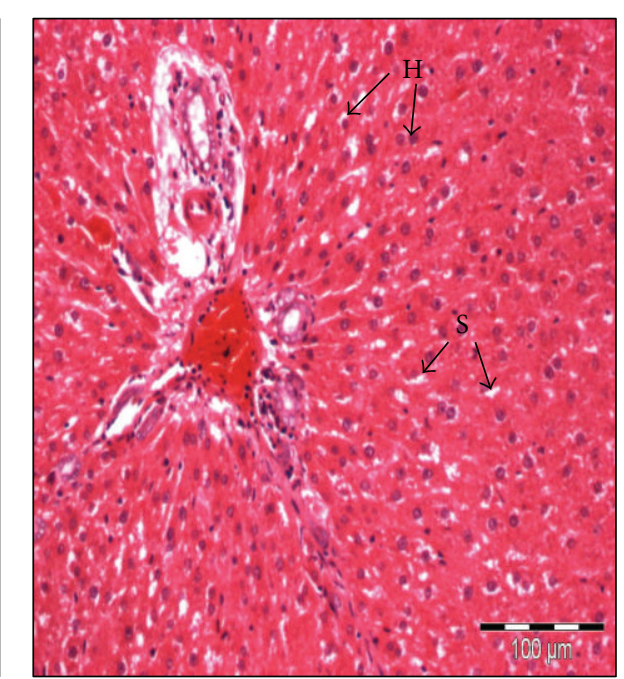

(ii)

(b)

Figure 6: Histological structure of liver from control (a) medium $0.14 \mathrm{~g} / \mathrm{kg}$ BW (b) group of male SD rat showing the Central vein (CV), hepatocyte $(\mathrm{H})$, the sinusoid $(\mathrm{S})$ and the portal vein (PV). The structure showed there were normal as compared to the control. (i) $4 \mathrm{x}$, (ii) 40x, (H\&E Staining).

\section{Conflict of Interests}

The authors declare that there is no conflict of interests regarding the publication of this paper.

\section{Acknowledgments}

The authors thank the Director General of Health, Ministry of Health, Malaysia, and also Director of the Institute for Medical Research (IMR), Kuala Lumpur, for the permission to publish this paper. This study was supported by the National Institute of Health, Ministry of Health, Malaysia. Thanks are also due to the staff at the Herbal Medicine Research Center for their contribution to this study. The authors are grateful to Dr. Naseem Malik from the Laboratory Animal Resource Unit, IMR, for rendering technical assistance. Thanks are also due to Dr. Murizal Zainol and Dr. Hussin Muhammad for reviewing the paper.

\section{References}

[1] H. C. Ong, B. N. Ruzalila, and P. Milow, “Traditional knowledge of medicinal plants among the malay villagers in Kampung Tanjung Sabtu, Terengganu, Malaysia," Indian Journal of Traditional Knowledge, vol. 10, no. 3, pp. 460-465, 2011.

[2] HMRC, Compendium Medicinal Plants Used in Malaysia, vol. 1, Herbal Medicine Research Centre, Institute for Medical Research, Kuala Lumpur, Malaysia, 2002. 
[3] K. L. Krishna, M. Paridhavi, and J. A. Patel, "Review on nutritional, medicinal and pharmacological properties of Papaya (Carica papaya Linn.)," Natural Product Radiance, vol. 7, no. 4, pp. 364-373, 2008.

[4] J. A. Osato, L. A. Santiago, G. M. Remo, M. S. Cuadra, and A. Mori, "Antimicrobial and antioxidant activities of unripe papaya," Life Sciences, vol. 53, no. 17, pp. 1383-1389, 1993.

[5] B. S. Nayak, L. P. Pereira, and D. Maharaj, "Wound healing activity of Carica papaya L. In experimentally induced diabetic rats," Indian Journal of Experimental Biology, vol. 45, no. 8, pp. 739-743, 2007.

[6] M. Indran, A. A. Mahmood, and U. R. Kuppusamy, "Protective effect of Carica papaya L leaf extract against alcohol induced acute gastric damage and blood oxidative stress in rats," West Indian Medical Journal, vol. 57, no. 4, pp. 323-326, 2008.

[7] A. A. Mahmood, K. Siddiq, and I. Salmah, "Wound healing acivity of Carica papaya L. aqueous leaf extract rats," Journal of Molecular and Advance Sciences, vol. 1, pp. 398-401, 2005.

[8] N. Otsuki, N. H. Dang, E. Kumagai, A. Kondo, S. Iwata, and C. Morimoto, "Aqueous extract of Carica papaya leaves exhibits anti-tumor activity and immunomodulatory effects," Journal of Ethnopharmacology, vol. 127, no. 3, pp. 760-767, 2010.

[9] A. Murukami, H. Ohigashi, and K. Koshimizu, "Possible antitumour promoting properties of traditional Thai food items and some of their active constituents," Asia Pasific Journal of Clinical Nutrition, vol. 3, pp. 185-191, 1994.

[10] A. Canini, D. Alesiani, G. D’Arcangelo, and P. Tagliatesta, "Gas chromatography-mass spectrometry analysis of phenolic compounds from Carica papaya L. leaf," Journal of Food Composition and Analysis, vol. 20, no. 7, pp. 584-590, 2007.

[11] S. M. N. Azmi, P. Jamal, and A. Amid, "Purification of Xanthine oxidase inhibitor from carica papaya leaves using reversed phase flash column chromatography (RPFCC)-high performance thin layer chromatography (HPTLC)," Australian Journal of Basic and Applied Sciences, vol. 6, no. 1, pp. 117-122, 2012.

[12] P. Melariri, W. Campbell, P. Etusim, and P. Smith, "Antiplasmodial properties and bioassay-guided fractionation of ethyl acetate extracts from Carica papaya leaves," Journal of Parasitology Research, vol. 2011, Article ID 104954, 7 pages, 2011.

[13] M. Yusha'u, F. C. Onourah, and Y. Murtala, "In-vitro sensitivity pattern of some urinary tract isolated to Carica papaya extracts," Bayero Journal of Pure and Applied Sciences, vol. 2, no. 2, pp. 7578, 2009.

[14] E. M. Burdick, "Carpaine: an alkaloid of Carica papaya-its chemistry and pharmacology," in Proceedings of the 8th Annual Meeting of the Society for Economic Botany, University of Miami, 1967.

[15] A. U. Ogan, "The basic constituents of the leaves of Carica papaya," Phytochemistry, vol. 10, no. 10, pp. 2544-2547, 1971.

[16] C. S. Tang, "New macrocyclic, $\Delta$ 1-piperideine alkaloids from papaya leaves: dehydrocarpaine I and II," Phytochemistry, vol. 18, no. 4, pp. 651-652, 1979.

[17] V. U. Khuzhaev and S. F. Aripova, "Pseudocarpaine from Carica Papaya," Chemistry of Natural Compounds, vol. 36, no. 4, p. 418, 2000.

[18] B. T. Green, S. T. Lee, K. E. Panter et al., "Actions of piperidine alkaloid teratogens at fetal nicotinic acetylcholine receptors," Neurotoxicology and Teratology, vol. 32, no. 3, pp. 383-390, 2010.

[19] L. Tona, K. Kambu, N. Ngimbi, K. Cimanga, and A. J. Vlietinck, "Antiamoebic and phytochemical screening of some Congolese medicinal plants," Journal of Ethnopharmacology, vol. 61, no. 1, pp. 57-65, 1998.
[20] M. B. Ekong, M. U. Akpan, T. B. Ekanem, and M. I. Akpaso, "Morphometric malformations in fetal rats following treatment with aqueous leaf extract of Carica papaya," Asian Journal of Medical Sciences, vol. 2, no. 1, pp. 18-22, 2011.

[21] P. B. Ayoola and A. Adeyeye, "Phytochemical and nutrient evaluation of Carica papaya (Pawpaw) leaves," International Journal of Research and Reviews in Applied Sciences, vol. 5, no. 3, p. 325, 2010.

[22] A. Afzan, N. R. Abdullah, S. Z. Halim et al., "Repeated dose 28-days oral toxicity study of Carica papaya L. leaf extract in Sprague Dawley rats," Molecules, vol. 17, no. 4, pp. 4326-4342, 2012.

[23] S. Z. Halim, N. R. Abdullah, A. Afzan, B. A. Abdul Rashid, I. Jantan, and Z. Ismail, "Study of acute toxicity of Carica papaya leaf extract in Sprague Dawley rats," Journal of Medicinal Plants Research, vol. 5, no. 10, pp. 1867-1872, 2011.

[24] S. Subenthiran, T. C. Choon, K. C. Cheong et al., "Carica papaya leaves juice significantly accelerates the rate of increase in platelet count among patients with dengue fever and dengue haemorrhagic fever," Evidence-Based Complementary and Alternative Medicine, vol. 2013, Article ID 616737, 7 pages, 2013.

[25] Ministry of Health (MOH), Principle and Guide to Ethical Use of Laboratory Animals, Institute for Medical Research, 2000.

[26] Organization for Economic Cooperation Development (OECD), Guideline for the Testing of Chemicals: Repeated Dose 90-Day Oral Toxicity Study in Rodents (OECD No. 408), 1998.

[27] Organization for Economic Cooperation Development (OECD), Guidance Document on the Recognition, Assessment and Use of Clinical Signs as Human Endpoints for Experimental Animals Used in Safety Evaluation, Environmental Health and Safety Monograph Series on Testing and Assessment (OECD \#19), OECD, 2000.

[28] N. Crichton, "Information point: tukey multiple comparison test," Journal of Clinical Nursing, vol. 8, pp. 299-304, 1999.

[29] P. R. Hinton, C. Brownlow, I. McMurray, and B. Cozens, SPSS Explained, Routledge, New York, NY, USA, 2004.

[30] J. T. Mukinda and P. F. K. Eagles, "Acute and sub-chronic oral toxicity profiles of the aqueous extract of Polygala fruticosa in female mice and rats," Journal of Ethnopharmacology, vol. 128, no. 1, pp. 236-240, 2010.

[31] N. Everds, "Hematology of the mouse," in The Laboratory Mouse, H. J. Hedrich, G. Bullock, and P. Petrusz, Eds., pp. 271285, Elsevier Academic Press, London, UK, 2004.

[32] S. K. Ramaiah, "A toxicologist guide to the diagnostic interpretation of hepatic biochemical parameters," Food and Chemical Toxicology, vol. 45, no. 9, pp. 1551-1557, 2007.

[33] I. H. Garba and G. A. Ubom, "Total serum lactate dehydrogenase activity in acute Plasmodium falciparum malaria infection," Singapore Medical Journal, vol. 46, no. 11, pp. 632-634, 2005.

[34] K. Kotoh, M. Enjoji, M. Kato, M. Kohjima, M. Nakamuta, and R. Takayanagi, "A new parameter using serum lactate dehydrogenase and alanine aminotransferase level is useful for predicting the prognosis of patients at an early stage of acute liver injury: a retrospective study," Comparative Hepatology, vol. 7, article 6, 2008.

[35] M. Preus, B. Karsten, and A. S. Bhargava, "Serum isoenzyme pattern of creatine kinase and lactate dehydrogenase in various animal species," Journal of Clinical Chemistry and Clinical Biochemistry, vol. 27, no. 10, pp. 787-790, 1989.

[36] O. B. Oloyede and T. O. Sunmonu, "Decrease in activities of selected rat liver enzymes following consumption of chemical 
effluent," Journal of Applied Science and Environmental Management, vol. 12, no. 2, pp. 95-100, 2008.

[37] S. A. Omer, "Normal values of some serochemical parameters in male and female German Shepherd dogs in Sudan," Assiut Veterinary Medical Journal, vol. 55, no. 120, pp. 110-115, 2009.

[38] A. M. Attia and H. M. Nasr, "Dimethoate -induced changes in biochemical parameters of experimental rat serum and its neutralization by black seed (Nigella sativa L.) oil," Slovak Journal of Animal Science, vol. 42, no. 2, pp. 87-94, 2009.

[39] P. A. Tarkang, G. A. Agbor, T. D. Armelle, T. L. R. Yamthe, K. David, and Y. S. Mengue Ngadena, "Acute and chronic toxicity studies of the aqueous and ethanol leaf extracts of Carica papaya Linn in Wistar rats," Journal of Natural Products and Plant Resources, vol. 2, no. 5, pp. 617-627, 2012. 


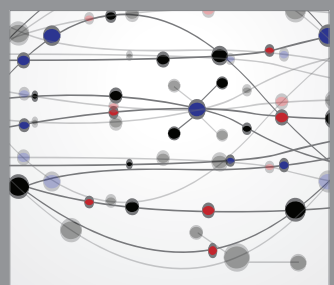

The Scientific World Journal
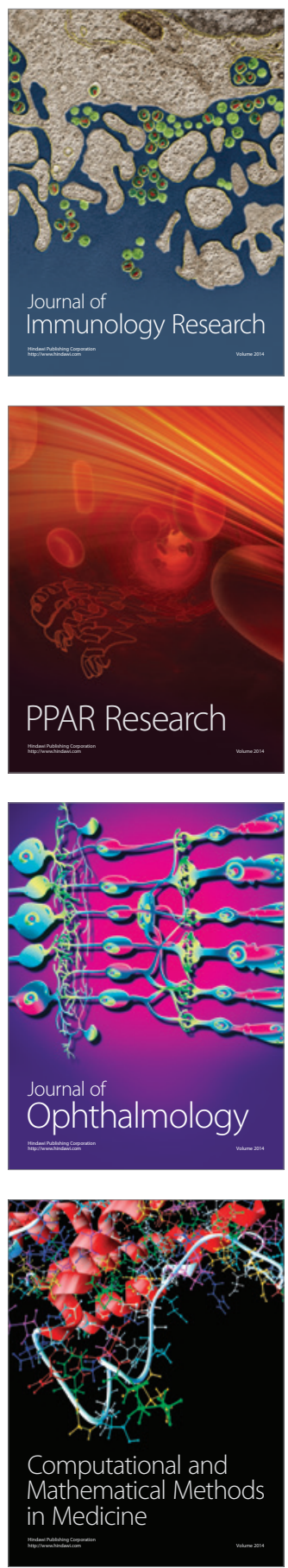

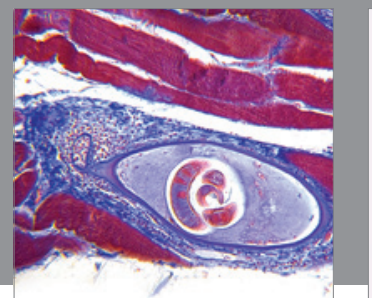

Gastroenterology

Research and Practice
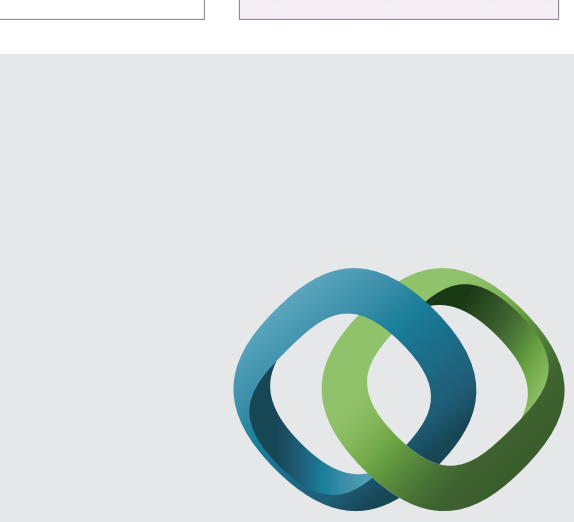

\section{Hindawi}

Submit your manuscripts at

http://www.hindawi.com
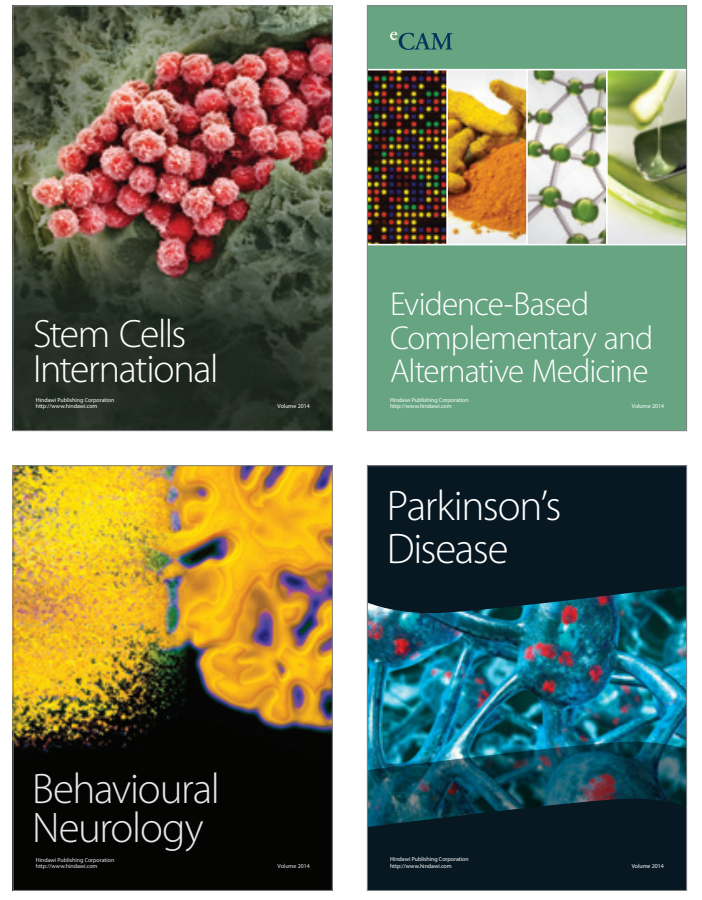
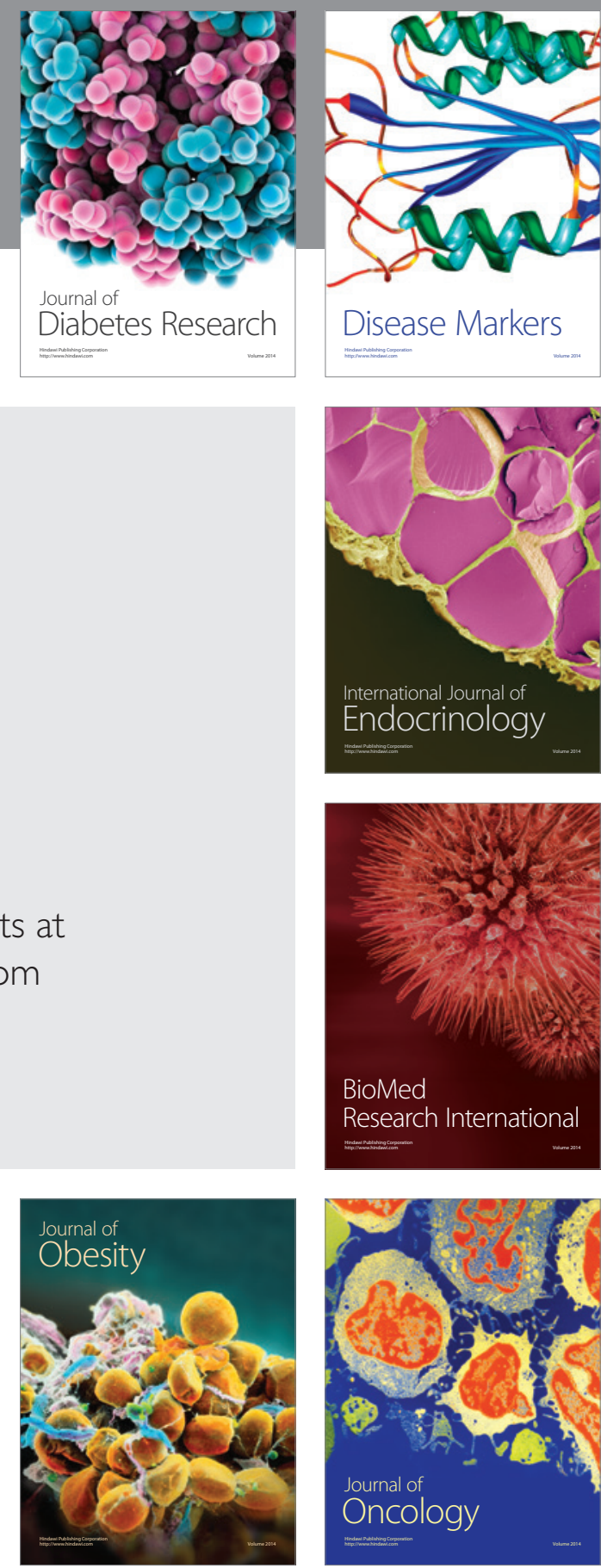

Disease Markers
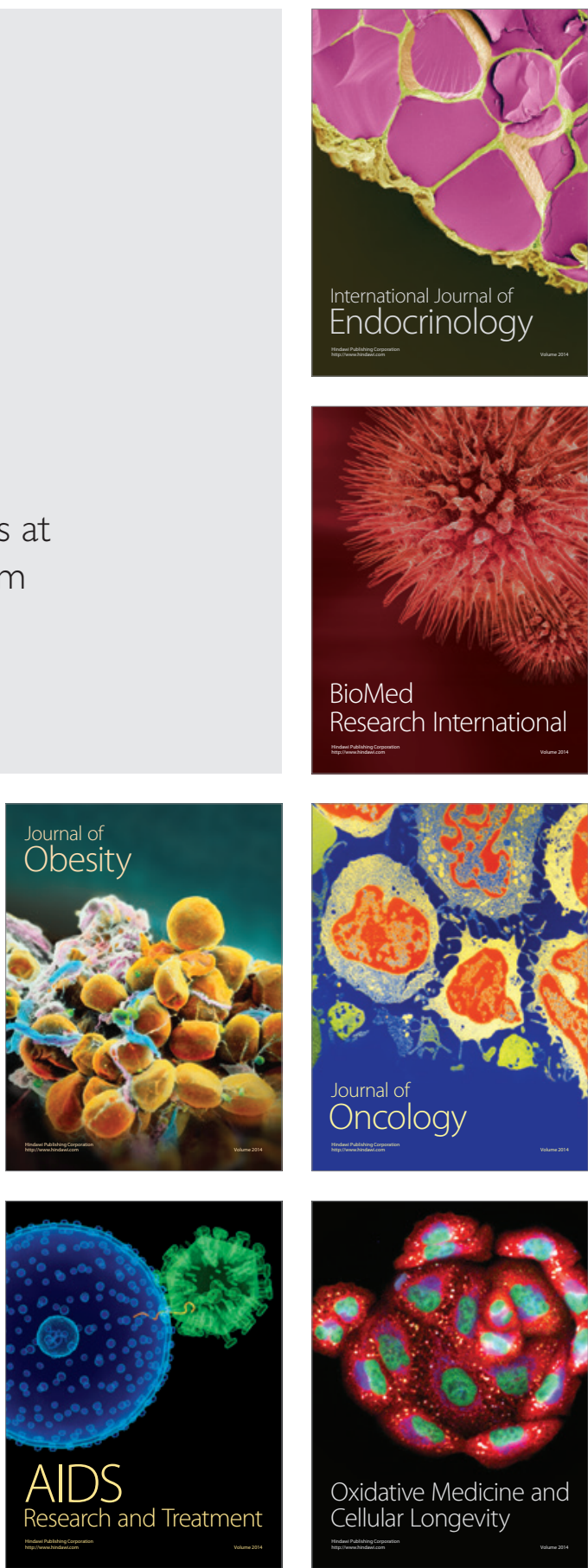